\title{
A MODEL FOR SELECTING PROJECT TEAM MEMBERS USING MULTICRITERIA GROUP DECISION MAKING
}

\author{
Luciana Hazin Alencar* \\ Adiel Teixeira de Almeida \\ Federal University of Pernambuco (UFPE) \\ Recife - PE, Brazil \\ lhazin@ufpe.br \\ * Corresponding author / autor para quem as correspondências devem ser encaminhadas \\ Recebido em 12/2008; aceito em 09/2009 \\ Received December 2008; accepted September 2009
}

\begin{abstract}
Selecting a project team is a complex multi-criteria decision-making problem. For this reason, one appropriate way to tackle such problems involves the use of multi-criteria decision aid methods. However, most of the decisions taken regarding the selection of project teams are made by a group of people. It is this which changes the focus of the problem by moving from one decision-maker (DM) to a group of DMs. Analysis needs to be extended in order to consider the preference structure of each individual group member. In this paper, we present a group decision model for project team selection based on a multi-criteria evaluation of the preferences of a client's representatives. It could be applied to any decision problem since it involves a group of decision makers whose preferences diverge little. An application of the model in order to select consultants for a construction project is presented.
\end{abstract}

Keywords: group decision; multicriteria decision making; project team selection.

\section{Resumo}

A seleção da equipe em um projeto é um problema de decisão multicritério. Uma forma apropriada de tratar tais problemas envolve o uso de métodos de apoio multicritério a decisão. Grande parte desses problemas envolve um grupo de decisores. Dessa forma, há uma mudança no foco da decisão de um decisor para um grupo de decisores. A análise deve ser ampliada no intuito de considerar a estrutura de preferência de cada membro do grupo. Nesse artigo, apresentamos um modelo aplicado à seleção de equipe de um projeto baseado na avaliação multicritério das preferências dos representantes do cliente do projeto. Pode ser aplicado a qualquer problema de decisão desde que envolva um grupo de decisores que tenham pequena divergência em relação às suas preferências. Uma aplicação para seleção de parte da equipe de um projeto de construção é apresentada.

Palavras-chave: decisão em grupo; decisão multicritério; seleção da equipe do projeto. 


\section{Introduction}

Project team selection is, in practice, a complex multi-criteria decision-making problem in which multiple decision-makers (DMs) evaluate the attributes required of consultants, contractors and subcontractors if they are to deliver the project at hand by checking such attributes against a large number of decision criteria.

According to Hatush \& Skitmore (1998), except where clients have identified a single criterion, such as a fixed price or determined a completion date, several criteria relating to contractors' likely performance (such as their technical experience, organizational structure, financial stability, past performance and safety records) need to be considered when selecting contractors.

Topcu (2004) points out that taking solely cost figures into consideration also raises quality problems during and upon completion of the project. He continues by saying that using a multi-criteria approach for evaluating contractors with respect to their economic and technological competences, quality standards, past performances, and other tangible and intangible characteristics may help to solve this problem.

For this reason, one appropriate way to tackle such problems involves the use of multicriteria decision aid methods. These have already been considered for selecting contractors, subcontractors and consultants (Hatush \& Skitmore, 1998; Topcu, 2004; Hsieh et al., 2004; Ng \& Chow, 2004; Cheung et al., 2002; Zavadskas \& Vilutiene, 2006; Alarcón \& Mourgues, 2002; Mahdi et al., 2002; Fong \& Choi, 2000; Al-Harbi, 2001; Brown et al., 2001; Ping Tserng \& Lin, 2002).

However, most of the decisions taken regarding the selection of project teams are made by a group of people. It is this which changes the focus of the problem by moving from one DM to a group of DMs. This introduces an important factor regarding the manner of aggregating the DMs' preference structures, which in many problems is not tackled appropriately. The analysis should be extended in order to consider, somehow, the preference structure of each individual group member, their different perceptions of the consequences and their several aspirations. Some models have been developed regarding contractor selection taking multicriteria group decision aid into consideration (Singh \& Tiong, 2005; Pongpeng \& Liston, 2003; Al-Reshaid \& Kartam, 2005).

In this paper, we present a multi-criteria group decision model for project team selection suitable for the problems of project team selection when there is little divergence among the DMs. An application of the model to the selection of consultants for a construction project is presented.

This paper examines the current practices for selecting project team members using a multicriteria group decision aid method (Section 2). Then, a theoretical basis regarding multicriteria decision aid methods and group decisions (Sections 3 and 4) is provided. A group decision model for selecting the project team is presented in Section 5. The problem of how to select a project team is structured and an application of the model is presented in Section 6 . In the final section, conclusions are presented. 


\section{Multi-criteria group decision models for project team selection}

Due to the nature of the selection problem, most of the models that have been developed use the multi-criteria decision aid approach to tackle the problem. Few models explicitly consider the group decision approach, although group decision problems are the most realistic ones for this type of decision problem. In this case, there is, generally, a person at a higher level in the hierarchy with the authority to attribute weights to the actors involved in the process. In most cases, a weighting average is applied for the final selection. It can also be seen, in some civil construction studies, that the way in which DMs' information is aggregated is developed without bearing in mind either their individual preference structures or the interactions between DMs.

Few studies about project team selection which take the group decision approach into consideration were found (Singh \& Tiong, 2005; Pongpeng \& Liston, 2003; Al-Reshaid \& Kartam, 2005). Singh \& Tiong (2005) proposed a fuzzy decision multi-criteria model for contractor selection. The method proposed in their study uses fuzzy set theory to tackle the uncertainty of the subjective nature of decision making with multiple DMs evaluating the alternatives relating to the decision criteria. During the process, each DM makes his or her individual evaluation. In the subsequent stage, the evaluations of all DMs are aggregated using fuzzy set theory. Pongpeng \& Liston (2003) developed a multi-criteria group decision aid, TenSeM, for tendering by contractors. Each DM makes his own evaluation regarding the alternatives $v$ criteria. An additive function is used to compute the final value of each company. Later on, the DMs' evaluations are aggregated using the sum of the values obtained by each DM for each company weighting and this is multiplied by the ratio of importance given to it by the DM. In this method, the authors regard all DMs as having the same importance in the decision process. Al-Reshaid \& Kartam (2005) proposed a methodology for contractor selection in the public sector for cases in which the contractor is also responsible for drawing up the design projects.

\section{Multi-criteria decision aid method}

The multi-criteria decision aid method provides the DM with tools that make it possible for him or her to solve problems taking into consideration different points of view, which are sometimes contradictory (Vincke, 1992).

Sevastjanov \& Figat (2007) state that there are different definitions of multicriteria decisionmaking (MCDM) in the literature, but the two pivotal problems are how to evaluate alternatives and how to compare them, according to the type of MCDM task it is intended to solve (choice, ranking, sorting, etc.). Many studies have been published on MCDM methods (Angelou \& Economides, 2008; Kull \& Talluri, 2008; Bitman \& Sharif, 2008; Meade \& Presley, 2002).

The PROMÉTHÉE VI, a method of the Preference Ranking Organization Method for Enrichment Evaluation (PROMÉTHÉE) family (Brans, 1982), is the one used in this study. This method was chosen since it permits the variation margins of the criteria weights to be incorporated. As we are addressing decision group problems where there is little divergence among the DMs, the divergence can be added to those weighting variations.

For the PROMÉTHÉE VI method application, the PROMÉTHÉE II method and the Geometrical Analysis for Interactive Aid (GAIA) procedure need to be used.

Pesquisa Operacional, v.30, n.1, p.221-236, Janeiro a Abril de 2010 
The PROMÉTHÉE method begins with the development of criteria scales to identify the intensity of preference of one alternative over another, by converting the attainment levels for alternatives into a $0-1$ scale ( 0 the worst; 1 the best). Six generalized criteria are given within PROMÉTHÉE (Figure 1 shows these generalized criteria) (Brans \& Mareschal, 2002).
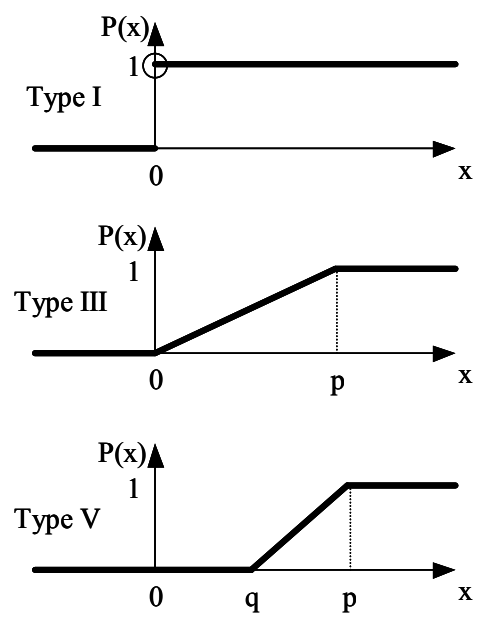
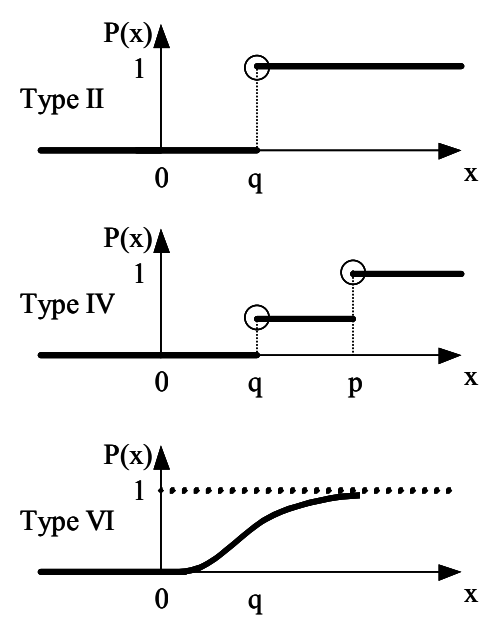

Figure 1 - Types of generalized criteria (Dias et al., 1998).

The relative importance of the criteria $\left(\mathrm{w}_{\mathrm{j}},\right)$ must be identified. A multi-criteria index $(\pi(\mathrm{a}, \mathrm{b}))$ is defined for all pairs of alternatives, which expresses how and to what degree $a$ is preferred over $b$ for all the criteria.

$$
\pi(a, b)=\frac{1}{w} \sum w_{j} F_{j}(a, b) \rightarrow w=\sum w_{j},
$$

For each alternative $a$, the mean preference intensity over all other alternatives is defined as $\phi^{+}(a)$. Next, the mean preference intensity of all other alternatives over alternative $a$ is defined as $\phi(a)$. The net flow $(\phi(a))$ is defined as the difference between the positive and the negative net flows. The higher the net flow is, the better the alternative is (Brans \& Mareschal, 2002; Belton \& Stewart, 2002).

The PROMÉTHÉE II method provides a complete pre-order ( $\mathrm{P}$ - preference, I - indifference) from the net flow $\phi(\mathrm{a}): a \mathrm{P} b$ if $\phi(a)>\phi(b) ; a \mathrm{I} b$ if $\phi(a)=\phi(b)$ (Brans, 1982).

As to the GAIA procedure, this consists of an interaction visual module which is complementary to PROMÉTHÉE (Mareschal \& Brans, 1988). The GAIA plane provides clear graphical information on the conflicting aspect of the criteria and on the impact of weights in the final decision, with several sensibility tools that enrich the vision that the DM has of his or her problem. It includes: (1) $\alpha_{i}$ points representing the alternatives; and (2) $c_{j}$ axes representing the criteria.

Finally, the PROMÉTHÉE VI method was developed due to the need to present a less prescriptive model in which some tolerance for the DM's space of freedom is preserved 
(Belton \& Stewart, 2002). A lower and an upper threshold should be defined, amongst which the weights can vary (Meade \& Presley, 2002):

$$
w_{j}^{-} \leq w_{j} \leq w_{j}^{+} \quad j=1,2, \ldots, k,
$$

where $w_{j}^{-}$and $w_{j}^{+}$are fixed numerical values.

These intervals can also be fixed starting from value $w_{j}$ that is known, which tolerates a percentage $\theta_{j}$ variation around this value:

$$
w_{j} \pm \theta_{j} \cdot w_{j}, \quad j=1,2, \ldots, k .
$$

\section{Group decision}

According to Jelassi et al. (1990), a group decision can be seen as the conjunction of different individual preferences into a single collective preference.

Iz \& Jelassi (1990) affirm that, in a typical group decision situation, the group members' preferences are a priori different from each other. Consequently, determining the best alternative solution for the multi-objective problem requires the preferences of individuals to be aggregated.

According to $\mathrm{Xu}$ (2005), generally, situations of conflict and disagreement over DMs' preferences arise. Therefore, an important issue is to find a group consensus to represent an opinion held in common by the group. Moreover, this author claims that there are many applications which necessitate differential weights in order to decide on group preferences.

Leyva-López \& Fernández-Gonzalez (2003) explain two approaches, generally used to aggregate group preferences: (1) A group consensus is needed only to define a potential set of actions. (2) The DMs should enter into agreement about the alternatives, criteria, performances, weights, thresholds and other parameters that are required to reach the solution, in accordance with the problematic chosen. This last approach is the one used in this study. Currently, various studies have been much consulted when considering group decision-making methods (Leyva-López \& Fernández-Gonzalez, 2003; Macharis et al., 1998; Costa et al., 2003; Jabeur \& Martel, 2007; Yeh \& Chang, 2008; Alencar \& Almeida, 2008; Morais \& Almeida, 2007).

From the studies developed, some models and software have been built. These include Team Expert Choice (Expert choice 2000 Team, 2001), GDSS PROMETHEE (Macharis et al., 1998), ELECTRE-GD (Leyva-López \& Fernández-Gonzalez, 2003), the multi-actor multicriteria analysis (MAMCA) method (Macharis et al., 2009).

\section{Multi-criteria group decision model}

The model presented should only be used for those cases in which there is little divergence among the DMs. This enables them to define an interval of variation for the weight of each criterion, i.e., a lower and an upper limit for the weight of each criterion.

The multi-criteria decision aid model is illustrated in Figure 2. In order to apply the PROMÉTHÉE VI method, the alternative net flows need to be calculated by the PROMÉTHÉE II method. With these net flows, the projections of the alternatives such as the 
criteria axes may be drawn on the GAIA plane. Using PROMÉTHÉE VI, the variation margins of the criteria weights stipulated by the DMs are added to these weights. When this area is projected onto the GAIA plane, the DMs' space of freedom is obtained. The decision stick can be oriented in any direction inside this space. Thus, any alternative situated in this direction is a good compromise on the DMs' preferences.

\section{DECISION MAKERS}

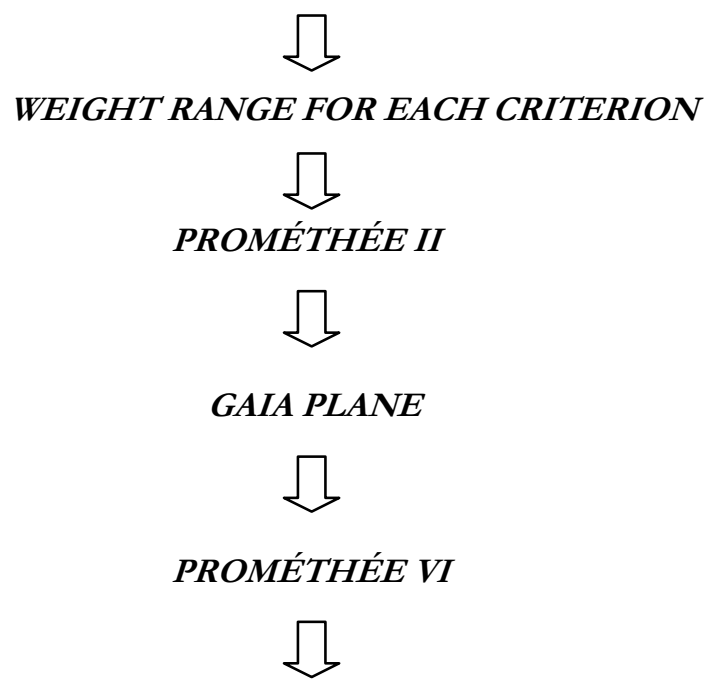

ALTERNATIVE SELECTED

Figure 2 - Multi-criteria group decision model.

First of all, all DMs involved must decide on the criteria that are involved in the decision process. This is the stage of the problem structuring. The alternatives must be identified and the criteria defined. Brainstorming can be used when the criteria are being defined and after that the criteria can be grouped according to each meaning until the set of criteria is defined. After this, the alternatives for each criterion are evaluated. For those criteria that have an objective evaluation, they are the same for all the DMs. For those criteria that have a subjective evaluation, the analyst must carry out a technical evaluation of subjective judgments. Once the first stage is complete, we can go to the next step.

During the second stage, the weight range for each criterion is established. The analyst must require each DM to establish the relative importance among the criteria. When all the weights are defined, the analyst will decide the weight range that encompasses all the DMs' weights. This is possible only in cases where there is no great divergence among the DMs.

For the PROMÉTHÉE application, the generalized criterion must be defined for each criterion. As there is little divergence among the DMs, these preference functions can be established during interactive discussion with the analyst. Once the central weights and the generalized criteria are defined, the PROMÉTHÉE II method can be applied. As a result, the net flows of the alternatives are obtained. With these, the projections of the alternatives such as the criteria axes may be drawn on the GAIA plane. 
Using PROMÉTHÉE VI, the variation margins of the criteria weights stipulated by the DMs are added to these weights. When this area is projected onto the GAIA plane, the DMs' space of freedom is obtained. The decision stick can be oriented in any direction inside this space. Thus, any alternative situated in this direction is a good compromise for the DMs' preferences.

The advantages of this approach as compared with others given in the literature (section 4) is that in cases where there is little divergence among the DMs' preferences, such divergences can be considered by incorporating a percentage weight variation (upper and lower) for each criterion considered in the process. So, it is not necessary to use a voting or aggregating system in order to consider the DMs' preferences in the decision process. The differences are incorporated in the weight variations and, after this stage, the decision process proceeds in the same way as that for a single DM.

\section{Numerical application}

In this section, the multi-criteria group decision model is applied to a procedure for selecting consultants, comprising the steps shown in Figure 3. Although we are using a numerical application in the present study due to the need to respect the confidentiality of company information, the data used is realistic and reflects the real world.

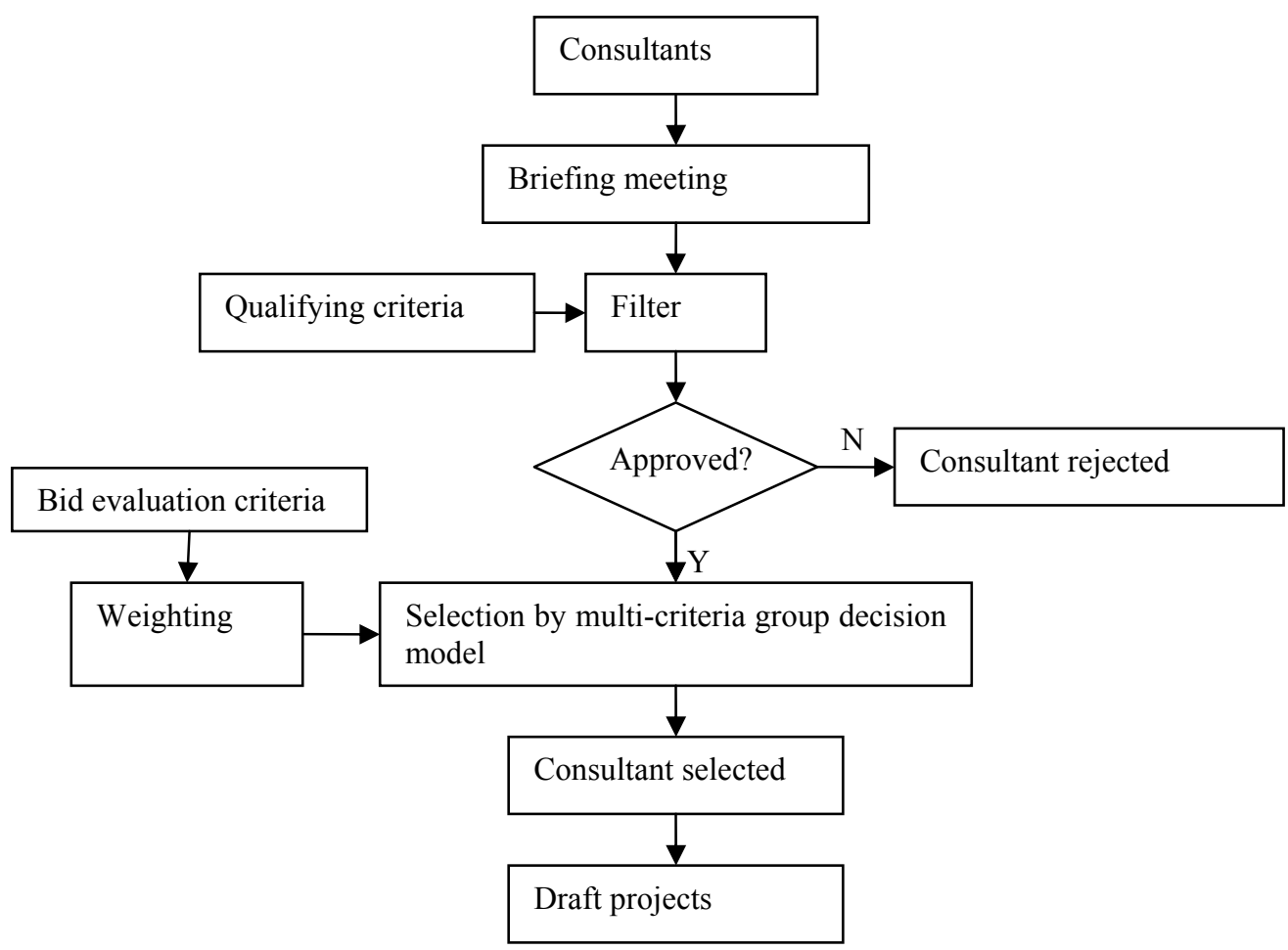

Figure 3 - Procedure for selecting consultants. 


\subsection{Structuring the project team selection problem}

By way of illustration, the multi-criteria group decision model presented in the previous section is used in order to select consultants for a construction project. This is followed by structuring the problem, which is used as a reference for the numerical application. The DMs and criteria used are based on Alencar \& Almeida (2008).

There are five DMs, who are the client's representatives. They define the decision criteria to be used, and that are formally required, to select the project team. The group of DMs representing the client is as follows:

$\mathrm{D}_{1}-\mathrm{a}$ representative of the Department of Engineering (a technical engineer);

$\mathrm{D}_{2}-$ a representative of the Department of Engineering (a quality engineer);

$\mathrm{D}_{3}$ - a representative of the Department of Engineering (a security and environment engineer);

$\mathrm{D}_{4}$ - a representative of the Department of Purchasing (a budget manager);

$\mathrm{D}_{5}$ - a representative of the Department of Procurement (a contract manager).

After that, the criteria to be used in the selection process of qualifiers and bid winners are presented. The criteria for qualifiers are given in Table 1 and those for bid winners in Table 2.

Table 1 - Qualifying criteria.

\begin{tabular}{|l|l|}
\hline \multicolumn{1}{|c|}{ Criterion } & \multicolumn{1}{c|}{ Description } \\
\hline Responsibility & $\begin{array}{l}\text { This refers to the extent to which the company conforms to } \\
\text { the regulations and standards demanded; that is, to the } \\
\text { existence of a quality certificate and of a security and } \\
\text { environmental policy. }\end{array}$ \\
\hline General experience & $\begin{array}{l}\text { This is about the general experience of the consultant } \\
\text { firm measured in square meters of properties built over } \\
\text { the last 5 (five) years; thus, all such companies should } \\
\text { have at least five years' experience. The attributes used } \\
\text { are: (i) the total square meterage actually built by the } \\
\text { construction company, and (ii) the total square meterage } \\
\text { of similar projects. The bidder who does not meet the } \\
\text { minimum values specified will be eliminated from the } \\
\text { process. }\end{array}$ \\
\hline Financial situation & $\begin{array}{l}\text { This refers to the financial situation of the bidder. The } \\
\text { attributes used are: general liquidity, current liquidity and } \\
\text { general solvency. The client will not accept bidders who } \\
\text { may be in a financial situation below the limit stipulated. }\end{array}$ \\
\hline
\end{tabular}


Table 2 - Criteria for bid winners.

\begin{tabular}{|l|l|}
\hline \multicolumn{1}{|c|}{ Criterion } & \multicolumn{1}{|c|}{ Description } \\
\hline $\mathrm{Cr}_{1}-$ Cost: & $\begin{array}{l}\text { This refers to the need to ensure that budgets are not } \\
\text { exceeded. Cost is measured in an objective way by } \\
\text { examining the average cost deviation for which the } \\
\text { company was responsible on projects it has carried out in } \\
\text { the last 5 years in relation to the planned cost. }\end{array}$ \\
\hline $\mathrm{Cr}_{2}-$ Culture: & $\begin{array}{l}\text { This is related to the willingness to incorporate new ideas } \\
\text { and concepts. }\end{array}$ \\
\hline $\mathrm{Cr}_{3}-$ Design: & $\begin{array}{l}\text { This is with a view to involving the construction } \\
\text { companies and sub-contractors who may have the skills } \\
\text { needed to help the project designers in their activities, thus } \\
\text { producing a structure which is appropriate and a project } \\
\text { which is stimulating intellectually. }\end{array}$ \\
\hline $\mathrm{Cr}_{4}-$ Quality: & $\begin{array}{l}\text { This aims to ensure that the quality of the project is } \\
\text { effectively translated into a physical construction of } \\
\text { quality, and one that furnishes a structure which has low } \\
\text { operational and maintenance costs. }\end{array}$ \\
\hline $\mathrm{Cr}_{6}-$ Experience: & $\begin{array}{l}\text { This corresponds to the total period of the project and } \\
\text { construction phase, the skill of planning correctly and } \\
\text { finalizing activities in accordance with the deadlines laid } \\
\text { down by the client. It is measured in an objective way by } \\
\text { the average of the schedule deviations for which the } \\
\text { company was responsible on projects it has carried out in } \\
\text { the last } 5 \text { years in relation to the planned schedule. }\end{array}$ \\
\hline $\begin{array}{l}\text { This considers the experience of key people who will work } \\
\text { on the project, measured in terms of the years of } \\
\text { experience of the engineers and project designers. }\end{array}$ \\
\hline
\end{tabular}

The criteria of culture, design and quality are measured in a subjective way by the analyst. He analyzes the questionnaires and other information gathered during the selection process. After the criteria are defined, the relative importance between them is established. The technique of direct attribution is used.

\subsection{Application of the model}

Following the description given earlier, each DM gives his or her own weights to each criterion. Later on, the variations occurring in the weight of each criterion are verified and a mean value for the weight is determined with a variation that encompasses the preferences of all DMs. After that, these weights are normalized.

Thus, since the existing divergence regarding the criteria weights is small, the variation range covers the preferences of all DMs, as illustrated in Table 3. 
Table 3 - Table of normalized weights of criteria.

\begin{tabular}{ccc}
\hline Criterion & $\boldsymbol{w}_{\mathbf{j}}$ & $\pm \boldsymbol{\theta}$ \\
\hline $\mathrm{Cr}_{1}$ & 0.118 & $30 \%$ \\
$\mathrm{Cr}_{2}$ & 0.176 & $30 \%$ \\
$\mathrm{Cr}_{3}$ & 0.294 & $50 \%$ \\
$\mathrm{Cr}_{4}$ & 0.176 & $10 \%$ \\
$\mathrm{Cr}_{5}$ & 0.118 & $10 \%$ \\
$\mathrm{Cr}_{6}$ & 0.118 & $10 \%$ \\
\hline
\end{tabular}

The stages of the procedure for selecting consultants - briefing meeting, filter and final selection - are presented below.

During the briefing meeting, all the consultants interested in the project are invited to take part in the meeting, and information relating to the type of project, location, estimated timescale and other basic data are presented. At this meeting, the applicant bidders are briefed on the objectives of the project and the process by which the selection will be made.

In the filter, the minimum acceptable levels of each attribute are used to eliminate unacceptable alternatives. Among the qualifying criteria presented in Section 6, only those regarding levels of responsibility and a minimum of 5 years' experience in construction projects are considered. Six companies are considered for the next stage.

In the selection stage, the DMs, in conjunction with the analyst, draw up a questionnaire which involves the bid evaluation criteria which do not have an objective measurement, defined in the previous stage. Questions will be compiled which supply relevant information to the project with regard to the bidding firm and which contribute to evaluating it when allied to the other sets of information collected throughout the process. Thus, each applicant bidder will receive a questionnaire, as well as a form on which he or she provides information about the people who have answered the questionnaire.

Based on the information collected, evaluations of the applicant bidding companies with regard to the defined criteria are conducted. The analyst evaluates the bidders with regard to culture, quality and design criteria, since this is a technical evaluation of subjective judgments. The following levels of preference, converted to a numerical scale to facilitate the evaluation of these subjective aspects, are presented in Table 4.

Table 4 - Scale for judging the importance of the culture, quality and design criteria.

\begin{tabular}{lc}
\hline \multicolumn{1}{c}{ Preference level } & Numerical scale \\
\hline Very Good & 5 \\
Good & 4 \\
Regular & 3 \\
Bad & 2 \\
Very Bad & 1 \\
\hline
\end{tabular}


The results, together with those of the quantitative criteria, form the decision matrix, as shown in Table 5.

Table 5 - Decision matrix.

\begin{tabular}{crrrrrr}
\hline Consultant & $\mathbf{C r}_{\mathbf{1}}$ & $\mathbf{C r}_{\mathbf{2}}$ & $\mathbf{C r}_{\mathbf{3}}$ & $\mathbf{C r}_{\mathbf{4}}$ & $\mathbf{C r}_{\mathbf{5}}$ & $\mathbf{C r}_{\mathbf{6}}$ \\
\hline Consultant 1 & 0.1 & 4 & 5 & 4 & 0.10 & 8 \\
Consultant 2 & 0.15 & 2 & 2 & 4 & 0.05 & 20 \\
Consultant 3 & 0.15 & 1 & 2 & 3 & -0.05 & 15 \\
Consultant 4 & 0.03 & 1 & 1 & 4 & 0.15 & 6 \\
Consultant 5 & -0.03 & 4 & 4 & 3 & 0.20 & 10 \\
Consultant 6 & 0.05 & 3 & 5 & 3 & 0.10 & 5 \\
\hline
\end{tabular}

Later, a group multi-criteria decision model is used as shown in Figure 2 presented in the previous stage.

In order to apply the PROMÉTHÉE II method, the intra-criteria information needs to be determined. A discussion with all the DMs is held, and the preference functions (generalized criteria) are established for each criterion, in an interactive way with the analyst. Since there is little divergence among the DM, a consensus is reached on the preference functions established during the group discussion.

Table 6 presents the generalized criteria and the parameters established (indifference threshold, $q$; preference threshold, $p$ ).

Table 6 - Additional information.

\begin{tabular}{l|cc}
\hline \multicolumn{1}{c|}{ Criterion } & Generalized criterion & Parameter(s) \\
\hline Cost & Type V & $\mathrm{q}=0.02$ \\
& & $\mathrm{p}=0.05$ \\
Culture & Type I & - \\
Design & Type I & - \\
Quality & Type I & - \\
Time & Type III & $\mathrm{p}=0.05$ \\
Experience & Type III & $\mathrm{p}=2$ \\
\hline
\end{tabular}


The net flows are calculated in accordance with PROMÉTHÉE II methodology. The result is presented in Table 7.

Table 7 - Alternative net flows.

\begin{tabular}{c|c}
\hline Consultant & Net flow \\
\hline Consultant 1 & 0.44 \\
Consultant 2 & 0.05 \\
Consultant 3 & -0.27 \\
Consultant 4 & -0.44 \\
Consultant 5 & 0.12 \\
Consultant 6 & 0.11 \\
\hline
\end{tabular}

With a view to establishing the net flows, PROMÉTHÉE VI is applied using PROMCALC software (Brans \& Mareschal, 1994), to which the margin of variation of the weights determined by the DM in the preliminary stage is added. In this way, what is identified is that the alternative of best commitment is alternative 1, i.e., consultant 1 , since it is the only alternative that is in the direction of the decision axis for the whole group of weights contained in the stipulated zone (see Figure 4).

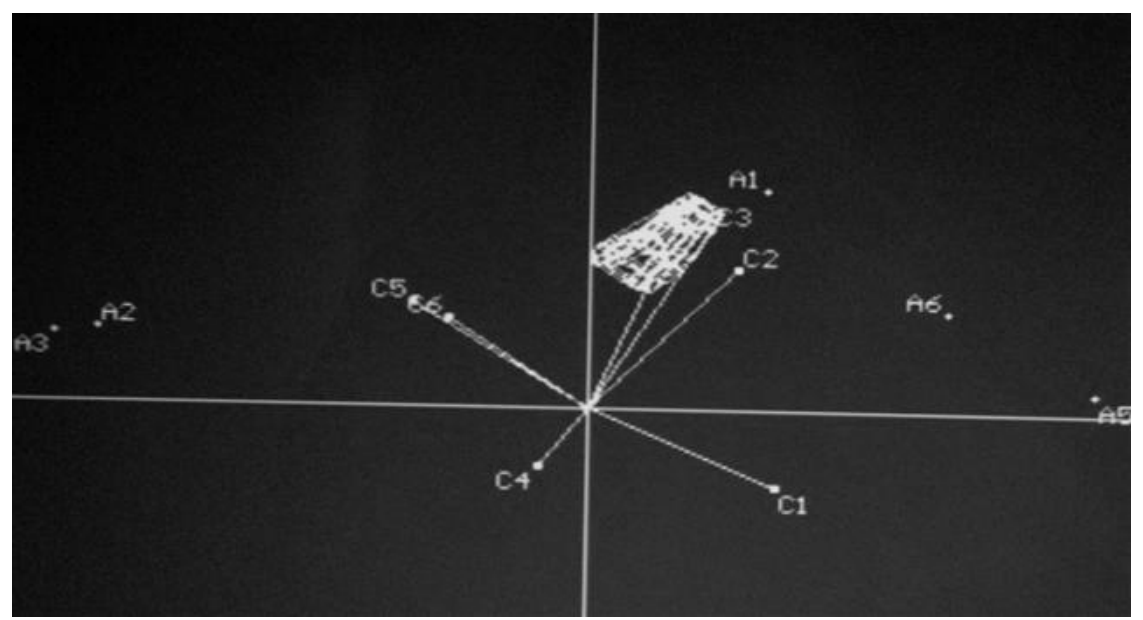

Figure 4 - PROMÉTHÉE VI - GAIA plane.

It is important to point out that PROMÉTHÉE VI can also be considered as a tool for sensitivity analysis, since it allows the area corresponding to the weighting variation to be visualized and it verifies whether the decision stick is indeed in the direction of the selected alternative.

Then, once selected, the consultant will receive the specifications for the projects and should present draft project proposals to the client or their representatives. 


\section{Concluding remarks}

Since the complexity of project management in the civil construction industry has been acknowledged, an increasing emphasis has been given to developing new ways to select project team members. The aim is to minimize conflicts among the different actors involved, in order to obtain better relationships among them and to meet the objectives of the project. These are usually centered on the delivery of the final product at the lowest possible cost, with quality, respecting the deadline and the scope defined, in such a way as to obtain the client's satisfaction.

This study presented a group multi-criteria decision aid model proposal for project team selection in the civil construction industry.

In general, decisions related to project team selection for civil construction projects involve a group of people, from different departments of an organization, who represent the client's interests. Few papers in the literature tackle the question of group decision. In general, they consider only one individual as responsible for the decision, which does not correspond to reality.

Two situations can be identified in this type of decision: a situation in which there is great divergence among the DMs' preferences and another in which there is little divergence among them. The focus of this study has been on the second situation. The occurrence of these situations can vary depending on whom the client chooses to represent it, and from project to project.

The PROMÉTHÉE VI method used in the model has shown itself to be appropriate; since there is no great divergence among the DMs, there is no great difficulty in their stipulating the variations of the weight of each criterion around a central value. A numerical application was performed to illustrate the model proposed for selecting consultants.

Thus, the model presented permits consultants to be selected who are most committed to the aim of a client. It may also be used in other applications that include a group decision problem and when there is little divergence among the DMs.

\section{Acknowledgments}

This study is part of a research program funded by the Brazilian Research Council (CNPq). The authors gratefully acknowledge the valuable suggestions made by anonymous reviewers to a previous version of this paper, which have contributed to make this a better final version.

\section{References}

(1) Alarcón, L. \& Mourgues, C. (2002). Performance modeling for contractor selection. Journal of Management in Engineering, 18(2), 52-60.

(2) Alencar, L. \& Almeida, A. (2008). Multicriteria Decision Group Model for Suppliers Selection. Pesquisa Operacional, 28, 321-337.

(3) Al-Harbi, K. (2001). Application of the AHP in project management. International Journal of Project Management, 19(1), 19-27. 
(4) Al-Reshaid, K. \& Kartam, N. (2005). Design-build pre-qualification and tendering approach for public projects. International Journal of Project Management, 23(4), 309-320.

(5) Angelou, G. \& Economides, A. (2008). A Decision Analysis Framework for Prioritizing a Portfolio of ICT Infrastructure Projects. IEEE Transactions on Engineering Management, 55(3), 479-495.

(6) Belton, V. \& Stewart, J. (2002). Multiple criteria decision analysis - an integrated approach. Kluwer Academic Publishers, London.

(7) Bitman, W. \& Sharif, N. (2008). A Conceptual Framework for Ranking R\&D Projects. IEEE Transactions on Engineering Management, 55(2), 267-278.

(8) Brans, J. \& Mareschal, B. (2002). PROMÉTHÉE - GAIA: une méthodologie d'aide à la décision en présence de critères multiples. Éditions de L’Université de Bruxelles, Bruxelles.

(9) Brans, J. (1996). The space of freedom of the decision maker modelling the human brain. European Journal of Operational Research, 92(3), 593-602.

(10) Brans, P. (1982). L'ingénierie de la décision. Elaboration d'instruments d'aide à la décision. La méthode PROMÉTHÉE. In: Colloque D'aide à la Décision. Université Laval, Québec, 183-213.

(11) Brans, J. \& Mareschal, B. (1994). PROMCALC and GAIA: a new decision support system for multicriteria decision aid. Decision Support Systems, 12(4-5), 297-310.

(12) Brown, D.; Ashleig, M.; Riley, M. \& Shaw, R. (2001). New project procurement process. Journal of Management in Engineering, 17(4), 192-201.

(13) Cheung, F.; Kuen, J. \& Skitmore, M. (2002). Multi-criteria evaluation model for the selection of architectural consultants. Construction Management and Economics, 20(7), 569-580.

(14) Costa, J.; Melo, P.; Godinho, P. \& Dias, L. (2003). The AGAP System: a GDSS for project analysis and evaluation. European Journal of Operational Research, 145(2), 287-303.

(15) Dias, L.C.; Costa, J.P. \& Clímaco, J.C. (1998). A parallel implementation of the PROMÉTHÉE method. European Journal of Operational Research, 104, 521-531.

(16) Expert Choice 2000 Team. (2001). Expert Choice, Inc, Pittsburgh.

(17) Fong, S. \& Choi, K. (2000). Final contractor selection using the analytical hierarchy process. Construction Management and Economics, 18(5), 547-57.

(18) Hatush, Z. \& Skitmore, M. (1998). Contractor selection using multicriteria utility theory: an additive model. Building and Environment, 33(2), 105-115.

(19) Hsieh, T.; Lu, S. \& Tzeng, G. (2004). Fuzzy MCDM approach for planning and design tenders selection in public office buildings. International Journal of Project Management, 22(7), 573-584.

(20) Iz, P. \& Jelassi, M. (1990). An interactive group decision aid for multi-objective problems: an empirical assessment. Omega, 18(6), 595-694. 
(21) Jabeur, K. \& Martel, J. (2007). An ordinal sorting method for group decision-making. European Journal of Operational Research, 180, 1272-1289.

(22) Jelassi, T.; Kersten, G. \& Ziont, S. (1990). An introduction to group decision and negotiation support. In: Readings in multiple criteria decision aid [edited by $\mathrm{C}$. Bana and Costa], Springer-Verlag, Berlin, 537-568.

(23) Kull, T. \& Talluri, S. (2008). A Supply Risk Reduction Model Using Integrated Multicriteria Decision Making. IEEE Transactions on Engineering Management, 55(3), 409-419.

(24) Leyva-López, J. \& Fernández-Gonzalez, E. (2003). A new method for group decision support based on ELECTRE III methodology. European Journal of Operational Research, 26(3), 14-27.

(25) Macharis, C.; De Witte, A. \& Ampe, J. (2009). The multi-actor, multi-criteria analysis methodology (MAMCA) for the evaluation of transport projects: Theory and practice. Journal of Advanced Transportation, 43(2), 183-202.

(26) Macharis, C.; Brans, J. \& Mareschal, B. (1998). The GDSS PROMÉTHÉE procedure: a PROMÉTHÉE-GAIA based procedure for group decision support. Journal of Decision Systems, 7, 283-307.

(27) Mahdi, I.; Riley, M.; Fereig, S. \& Alex, A. (2002). A multi-criteria approach to contractor selection. Engineering Construction and Architectural Management, 9(1), 29-37.

(28) Mareschal, B. \& Brans, J. (1988). Geometrical representation for MCDM, the GAIA procedure. European Journal of Operational Research, 34(1), 69-77.

(29) Meade, L. \& Presley, A. (2002). R\&D project selection using the analytic network process. IEEE Transactions on Engineering Management, 49(1), 59-66.

(30) Morais, D.C. \& Almeida, A.T. (2007). Group decision-making for leakage management strategy of water network. Resources, Conservation and Recycling, 52(2), 441-459.

(31) Ng, S. \& Chow, L. (2004). Framework for evaluating the performance of engineering consultants. Journal of Professional Issues in Engineering Education and Practice, 130(4), 280-288.

(32) Ping Tserng, H. \& Lin, P. (2002). An accelerated subcontracting and procuring model for construction projects. Automation in Construction, 1(11), 105-125.

(33) Pongpeng, J. \& Liston, J. (2003). Contractor ability criteria: a view from the Thai construction industry. Construction Management and Economics, 21(3), 267-282.

(34) Sevastjanov, P. \& Figat, P. (2007). Aggregation of aggregating modes in MCDM: synthesis of Type 2 and Level 2 fuzzy sets. Omega, 35, 505-523.

(35) Singh, D. \& Tiong, R. (2005). A fuzzy decision framework for contractor selection. Journal of Construction Engineering and Management, 131(1), 62-70.

(36) Topcu, Y. (2004). A decision model proposal for construction contractor selection in Turkey. Building and Environment, 39(4), 469-481.

(37) Vincke, P. (1992). Multicriteria decision-aid. Wiley, Bruxelles. 
(38) $\mathrm{Xu}, \mathrm{Z}$. (2005). Deviation measures of linguistic preference relations in group decision making. Omega, 33, 249-254.

(39) Yeh, C-H. \& Chang, Y-H. (2008). Modeling subjective evaluation for fuzzy group multicriteria decision making. European Journal of Operational Research, doi:10.1016/j.ejor.2007.12.029.

(40) Zavadskas, E. \& Vilutiene, T. (2006). A multiple criteria evaluation of multi-family apartment block's maintenance contractors: I- model for maintenance contractor evaluation and the determination of its selection criteria. Building and Environment, 41(5), 621-632. 